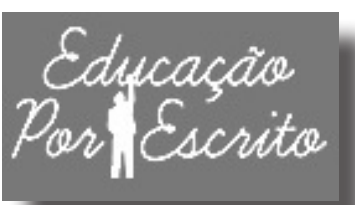

ARTIGO

Editor
Maria Inês Côrte Vitoria
PUCRS, RS, Brasil
Equipe Editorial
Pricila Kohls dos Santos
PUCRS, RS, Brasil
Marcelo Oliveira da Silva
PUCRS, RS, Brasil
Carla Spagnolo
PUCRS, RS, Brasil
Rosa Maria Rigo
PUCRS, RS, Brasil

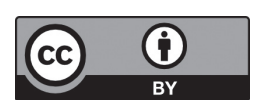

A matéria publicada neste periódico é licenciada sob forma de uma Licença Creative Commons - Atribuição 4.0 Internacional. http://creativecommons.org/licenses/by/4.0/

\section{Estado do Conhecimento sobre a afetividade na aprendizagem na iniciação esportiva: influências da relação professor/treinador-aluno}

State of the Kknowledge on affectiveness in the learning and the early stage of sports practice: influences of the relation of the teacher/coach-pupil relationship

Michelle Guiramand ${ }^{a}$

RESUMO: Embora se saiba que o desempenho de um movimento envolve processos relacionados aos domínios motor, afetivo-social e cognitivo, percebe-se que na iniciação esportiva muitas vezes a aprendizagem vem desacompanhada de manifestações de afetividade, que nesses processos se dá por meio das relações professor/ treinador-aluno. O trabalho objetiva identificar o estado do conhecimento sobre a afetividade na aprendizagem na iniciação esportiva a partir da relação professor/treinador-aluno, tendo como base de dados as teses e dissertações do banco de dados da CAPES, dos anos de 2011 e 2012. A tabela para a organização de materiais incluiu o processo de categorização, com bases na metodologia da análise de conteúdo. Identificou-se que há estreita afinidade entre a afetividade e a aprendizagem na iniciação esportiva, considerando-se a relação professor/ treinador-aluno como o pilar desse processo. A figura do professor/treinador e os desdobramentos das suas relações com o aluno-atleta na iniciação esportiva foi a temática transversal, que perpassou todas as categorias de análise nessa construção do estado do conhecimento.

Palavras-chave: Estado do conhecimento. Banco de teses CAPES. Afetividade. Relação professor-aluno. Iniciação esportiva.

ABSTRACT: Although it is known that the performance of a movement involves processes related to the motor, affective-social and cognitive domains, it is acknowledged that in early stages of sports learning practice often overlooks affective manifestations, that in these processes is accomplished through the relations between teacher/coach and pupils. The paper aims at identifying the status of knowledge on affectiveness in the early stages of sports learning experiences starting with the teacher/coach-pupil relationship, as based upon the data from dissertations and theses of the CAPES database in the years 2011 and 2012. The table for the organizing of materials included the categorization process on the bases of the content analysis methodology. It was found that there is a close affinity between affectiveness and learning in the beginning of sports life, considering the teacher/coach-pupil relation as the milestone of this process. The trainer teacher figure and the unfoldings of their relationship with the athlete pupil in the beginning of sports practice was the transversal theme, which went all the way throughout all analyses categories in this building of a knowledge state.

Keywords: Knowledge state. CAPES theses database. Affetiviness. Teacher-pupil relationship. Early sports experiences.

a Doutoranda do Programa de Pós-Graduação em Educação da PUCRS; Professora e coordenadora do curso de bacharelado da Faculdade de Educação Física e Ciências do Desporto da PUCRS. 
aprendizagem esportiva é um processo de longo prazo, observável pela competência em realizar uma habilidade

motora específica e, em alguns esportes, há a necessidade de uma iniciação e especialização precoce. Nestes casos, o atleta começa sua vida no esporte entre 5 e 7 anos, idade na qual ainda não está maturado tanto física quanto emocionalmente. Esse processo de aprendizagem depende de vários aspectos relacionados entre si, ligados aos domínios do comportamento humano: cognitivo, afetivo-social e motor. No entanto, mesmo trabalhando com crianças, treinadores esportivos dão grande ênfase e importância à parte técnica nos processos de aprendizagem de movimentos específicos ainda na iniciação esportiva, demonstrando pouca ou nenhuma afetividade, não sendo raro observar situações de choro e angústia dos jovens atletas durante uma sessão de treino, em função do tratamento recebido.

Estando os domínios do comportamento humano, citados, ligados à aprendizagem esportiva, seria plausível se questionar por que a afetividade estaria dissociada desse processo, sobretudo quando se conhece a existência de estudos como os de Mosquera e Stobäus (2006) e Leite (2012) que comprovam as relações da cognição com a afetividade. Portanto, se para ocorrer a aprendizagem de algum movimento está envolvida também a cognição e essa tem relações diretas com a afetividade, é apropriado pensar na possibilidade de melhores desempenhos esportivos com situações mais evidentes de afetividade dos treinadores de modalidades esportivas de iniciação e especialização precoce. É importante ressaltar também que a demonstração de afetividade aparece na relação professor-aluno, tornando-se essa relação fundamental para que os processos de aprendizagem se desenvolvam.

Considerando que a afetividade é um elemento importante para a aprendizagem; que a aprendizagem na iniciação esportiva envolve os domínios afetivo, motor e cognitivo, e que a manifestação de afetividade nesses processos se dá por meio das relações professor/treinador-aluno o objetivo desse estudo é identificar o estado de conhecimento sobre a afetividade na aprendizagem e iniciação esportiva a partir da relação professor/treinadoraluno.

Esse estudo teve como fonte teses e dissertações publicadas no banco de teses da CAPES, limitadas nos anos de 2011 e 2012 e obedeceu ao processo de categorização. De duas categorias iniciais surgiram quatro categorias emergentes, ponto de partida para a pesquisa. Primeiramente, o texto discorre sobre a aprendizagem na iniciação esportiva, contextualizando e caracterizando as práticas dentro desse estágio no esporte. Na sequência, entra nos conceitos da afetividade e de como esta pode influenciar a aprendizagem, seguido das questões que emergem da relação professor-aluno. Em seguida apresenta as opções metodológicas e a análise da produção científica no país acerca da afetividade na aprendizagem na iniciação esportiva a partir da relação professor/treinadoraluno. 


\section{Aprendizagem na iniciação esportiva}

De acordo com Barbanti (2006) existem três considerações para se desenvolver uma definição de esporte: refere-se a tipos específicos de atividades, depende das condições sob as quais as atividades acontecem, depende da orientação subjetiva dos participantes envolvidos nas atividades. Para o autor (op. cit., p. 55), muitos sociólogos do esporte o caracterizam como uma "forma de competição que ocorre sob condições formais e organizadas", confirmando o esporte como "uma atividade física competitiva que é institucionalizada".

Competição neste caso é definida como um processo através do qual o sucesso é medido diretamente pela comparação das realizações daqueles que estão executando a mesma atividade física, com regras e condições padronizadas. Institucionalização é um conceito sociológico que se refere a um conjunto de comportamentos normalizados ou padronizados durante um certo tempo e de uma situação para outra. (BARBANTI, 2006, p. 55)

Essa institucionalização inclui elementos como regras padronizadas, onde o cumprimento das mesmas e o programa de competições são feitos por entidades oficiais. Atletas e treinadores necessitam desenvolver estratégias e programas de treinamento para aumentar suas chances de sucesso e "a aprendizagem das habilidades esportivas se torna mais formalizada", as exigências da atividade se tornam mais complexas e precisam ser aprendidas sistematicamente (BARBANTI, 2006, p. 56).

Neste sentido, a ideia de competição pode ser vista como uma forma de direcionar a aprendizagem na iniciação esportiva, com o intuito de se alcançar, desde as primeiras fases dentro do esporte, o melhor resultado possível. $\mathrm{Na}$ busca pela melhor performance, professores e treinadores passam a exigir do atleta, mesmo nas etapas iniciais da aprendizagem de movimentos específicos, um altíssimo grau de aptidão motora, conforme regras previamente estabelecidas. O sistema de treinamento passa a se constituir em um conjunto de métodos visando práticas futuras. Contrapondo essa concepção de iniciação esportiva Santana $(2005$, p. 1) afirma que:

[...] a iniciação esportiva é um fenômeno complexo, carregado de sensibilidade, que não permite, a priori, a fixação de uma gênese, pois contempla uma série de unidades coexistentes as quais se inter-relacionam e desencadeiam uma quantidade generosa de implicações que interferem no processo de desenvolvimento humano da criança esportista. 
Assim, a aprendizagem esportiva está permeada por uma gama complexa de relações com o desenvolvimento e a aprendizagem motora, o ambiente sociocultural, a pedagogia dos esportes e a capacidade e competência dos técnicos envolvidos. Muitas questões podem ser levantadas na abordagem desse tema, que não se resumem apenas na observação do desempenho de habilidades motoras exibidas. Kunz (2006, p. 86) sugere ainda que os sujeitos na aprendizagem motora estão envolvidos na sua totalidade, onde dimensões perceptivo-cognitivas, emocionais-afetivas, sociais e motoras estarão influenciando a "perspectiva externa da realização dos movimentos".

Para Gallahue, Ozmun e Goodway (2013, p. 84) "tanto o processo como os produtos do desenvolvimento motor são influenciados por uma ampla variedade de fatores que operam isolada e conjuntamente." Como um produto do desenvolvimento motor, a aprendizagem esportiva pode estar vinculada à hereditariedade, às vivências anteriores, ao ambiente e às exigências da tarefa de movimento. Entende-se, também, que o desenvolvimento de habilidades motoras ocorre dentro de uma sequência fixa, porém com ritmo variável de indivíduo para indivíduo. Com isto, para os autores citados "cada pessoa é singular e possui o seu próprio cronograma de desenvolvimento, que é uma combinação entre hereditariedade individual e as influências ambientais" (op. cit., p. 84).

No entendimento do desenvolvimento e da aprendizagem motora está presente a importância de se adquirir habilidades em fases anteriores da vida que formarão as bases para as próximas aprendizagens. Assim, compreendese que a aprendizagem estará subordinada às formas como essas bases foram estabelecidas.

Tani et al (1988) afirmam que essa sequência nos processos de aprendizagem sugere a necessidade das crianças serem guiadas a partir das características de cada fase, do contrário é bem provável que se corra o risco de estabelecer objetivos, métodos e conteúdos de ensino desconectados de suas necessidades e expectativas, tendo como consequência no resultado falta de motivação e perda de interesse pela prática em questão. Essa situação pode ser vista com certa frequência, na medida em que a cobrança exacerbada dentro de uma sessão de treino pode estar totalmente desconectada das perspectivas da criança.

Para Miranda e Bara Filho (2008, p.144) um programa de treinamento esportivo destinado à crianças e adolescentes requer a "prevalência de fatores positivos sobre negativos, fato que, por vezes, não acontece".

Segundo Haywood e Getchell (2010, p.272) os profissionais que trabalham com crianças necessitam ter conhecimento acerca da autoestima e das suas influências, compreendendo que essa é "amplamente influenciada por comunicações verbais e não verbais daqueles que lhes são significativos, incluindo pais, irmãos, amigos, professores e treinadores". Portanto, a maneira como o professor/treinador irá falar a uma criança, o tom de voz que irá utilizar, seu gestual e as palavras que irá escolher são de fundamental importância em todo esse complexo processo que resulta na aprendizagem. 
A forma como o professor/treinador irá trabalhar com uma criança na fase da aprendizagem na iniciação esportiva ou a influência que exercerá sobre sua autoestima poderão ser decisivas para os resultados imediatos e futuros. Em modalidades esportivas de iniciação precoce, nota-se, normalmente, que os treinadores buscam um nível performático e de excelência desde muito cedo, exigindo e cobrando do pequeno atleta um elevado padrão de competência motora. Observa-se, muitas vezes, treinadores não respeitando os estágios de maturação da criança, fazendo expressões faciais e comentários verbais, acompanhados de xingamentos, sem nenhuma demonstração de afetividade, o que pode influenciar em sua autoestima e motivação.

\section{Afetividade}

A literatura apresenta divergência sobre o conceito de afetividade, não sendo raro haver confusão com os termos emoção, afeto, sentimento, paixão, entre outros. Normalmente, esses vocábulos são utilizados como sinônimos, no entanto para Ruiz e Oliveira $(2005$, p.6) a afetividade é um termo que define os afetos humanos, de uma maneira mais estrita, e também as nuances de sentimentos de agrado ou desagrado, enquanto que o afeto pode designar "qualquer espécie de sentimento e (ou) emoção associada a ideias ou a complexos de ideias". As autoras afirmam ainda que a historia da educação evidencia uma perda na dimensão afetiva nas formas de ações pedagógicas e que uma tendência de se separara-la da dimensão cognitiva sempre esteve presente.

O afeto é considerado a energia que move as ações dos seres humanos, pois sem a troca, calor e a afabilidade não há motivação nem interação entre os sujeitos, o que pode dificultar o desenvolvimento da inteligência (SANTOS, 2012, p. 113).

A despeito da natureza subjetiva dos fenômenos afetivos, estes se tornam dependentes da intervenção do meio sociocultural, por meio da qualidade das relações com outros indivíduos. A afetividade, por outro lado, pode assumir um significado mais amplo, relacionado às vivências dos sujeitos e a uma maior variedade de manifestações, inclusive sentimentos e emoções (TASSONI, 2000).

Portanto, ao pensarmos que todas as dimensões humanas estão interligadas, podemos ver em uma situação de aprendizagem esportiva não apenas o domínio motor como o único a ser desenvolvido, mas, também, os domínios cognitivo e afetivo. No entanto, o domínio afetivo não aparece com a mesma importância dos outros dois, sendo separado de forma evidente na maioria das situações de aprendizagem na iniciação esportiva, contrapondo o pensamento de Mosquera e Stobäus (2006, p. 125) de que a afetividade exerce um papel essencial e significativo para 
a vida humana, sobretudo quando se pensa na formação de indivíduos mais saudáveis e "capazes de tomar decisões sábias e inteligentes". Além disto, os autores alegam que a afetividade e as emoções estão em profunda relação com a razão, e que existe uma grande influência dessas sobre o funcionamento cerebral. Leite (2012) acrescenta ainda que para pensar em uma prática pedagógica é fundamental refletir e discutir sobre a dimensão afetiva, uma vez que essa estará entrelaçada à dimensão cognitiva.

Em uma rápida análise dos mecanismos envolvidos para a realização de um gesto motor, compreende-se que a coordenação para executar tal gesto depende de processos cerebrais complexos, envolvendo a cognição, bem como estarão envolvidos processos afetivos e emoções, uma vez que estão relacionados entre si. Desse modo, as manifestações de afetividade do treinador poderão ser decisivas para o resultado da aprendizagem e performance do movimento. Damásio (2006) completa essa ideia afirmando existir uma afinidade entre a razão e as emoções, relacionando o raciocínio e a tomada de decisão ao domínio pessoal e social, envolvidos nos sentimentos e ligados de alguma forma ao processamento dos sinais do corpo.

Tassoni (2000, p. 7) defende o pensamento de que "a afetividade que se manifesta na relação professor aluno constitui-se elemento inseparável do processo de construção do conhecimento", enquanto Santos (2012) diz que a afetividade tem papel essencial na construção e manutenção das relações interpessoais, sendo objeto de estudo e reflexão fundamental nas relações professor-aluno.

\section{Relação professor/treinador-aluno}

Para Marchesi (2008) a base do ensino está essencialmente fundamentada nas relações interpessoais, entendendo que as experiências emocionais são perenes. $\mathrm{O}$ autor ainda afirma que a profissão do professor é repleta de emoção, e que se faz necessário entender a potencialidade de suas possibilidades, não esquecendo possíveis consequências negativas. Com isso, a relação professor-aluno nunca é neutra, pois estará sempre carregada de algum tipo de emoção que poderá, em maior ou menor escala interferir nos resultados da aprendizagem.

Costi (2013) diz que o professor é responsável por desencadear muitos processos que estabelecem conexões e associações no cérebro, afirmando ainda que a complexidade da aprendizagem ocorre na relação professor-aluno, onde nessa relação existe a projeção de múltiplos sentimentos. Concordando com essa ideia Belotti e Faria (2010, p. 1) afirmam ser através de uma relação professor-aluno positiva que se amplia a perspectiva de um maior aprendizado, onde estarão envolvidos interesses e intenções, dizendo que a "força da relação professor-aluno é significativa e acaba produzindo resultados variados nos indivíduos." 
No esporte, essa relação se dá entre o treinador e o atleta, em qualquer idade e qualquer nível de desempenho. $\mathrm{Na}$ prática esportiva, o treinador é a figura com grande responsabilidade por desencadear os processos referidos, sendo capaz, inclusive, de motivar ou interromper a continuidade do atleta em uma determinada modalidade.

Existe também o indicativo de que o treinador, desde as primeiras etapas da aprendizagem na iniciação esportiva, deposita suas expectativas e anseios no atleta, preocupando-se excessivamente com o rendimento e os resultados. O reflexo dessa busca pelo desempenho irá conduzir sua relação e as formas de acolhida ao atleta, podendo essa estar permeada por sentimentos instáveis e, muitas vezes, confusos para a criança.

Para Becker (2000) a fase da aprendizagem esportiva deve ser baseada na motivação, destacando também a importância dos aspectos afetivos na interação do atleta com o treinador. $O$ autor ainda defende a valorização do esforço em comparação aos resultados em competições, afirmando também que os transtornos na relação professor/treinador-aluno/atleta são apontados como um motivo relevante de abando precoce do esporte.

Leite (2012, p. 355) diz que "as relações que se estabelecem entre o sujeito, o objeto de conhecimento e o agente mediador também são profundamente marcadas pela dimensão afetiva, uma vez que produzem impactos subjetivos no sujeito." O autor (op. cit., p. 355) defende a ideia de que esses impactos provocam, em determinadas situações, oscilações de "aproximação ou de distanciamento entre o sujeito e o referido objeto de conhecimento", acrescentando ainda que para pensar em uma prática pedagógica é fundamental refletir e discutir sobre a dimensão afetiva, uma vez que essa estará entrelaçada à dimensão cognitiva.

Para Lopes e Samulski (2004, p. 52) "o técnico que consegue desenvolver bons níveis de integração e comunicação dentro de sua equipe, terá um elemento diferencial em relação aos outros treinadores". No entanto, observa-se, muitas vezes, uma relação entre treinador e atleta vertical e autoritária, onde é de inteira responsabilidade do primeiro todas as tomadas de decisão em todos os aspectos do treinamento. Percebe-se que esse tipo de postura pode, em alguma medida, ocasionar as situações de aproximação ou distanciamento com o objeto de conhecimento, como referido anteriormente, sendo a mediação do treinador decisiva para a aprendizagem no esporte.

A compatibilidade do relacionamento treinador-atleta existe quando há boa comunicação entre eles, reconhecimento pelos esforços e rendimentos e quando o treinador procura auxiliar na satisfação das necessidades dos atletas. (MIRANDA; BARA FILHO, 2008, p. 151-152) 


\section{Opções metodológicas e resultados}

O estado do conhecimento ou estado da arte é compreendido como uma descrição e análise da produção científica acerca de um tema ou objeto de estudo, podendo ser delimitado por elementos como data, local e tipo de publicação. Para Romanowski e Ens (2006, p. 39) o estado do conhecimento ou estado da arte significa "uma contribuição importante na constituição do campo teórico de uma área de conhecimento", no sentido de que aponta restrições acerca do campo em que a pesquisa se desenvolve, bem como suas lacunas de disseminação.

A construção do estado do conhecimento desse estudo começou a partir dos questionamentos sobre a afetividade na aprendizagem esportiva por meio da relação professor/treinador-aluno. A base de dados sobre a qual ocorreu esse estudo é constituída pelas teses e dissertações do banco de dados da CAPES, dos anos de 2011 e 2012, disponível no endereço eletrônico <http://www.capes.gov.br>, que tem como objetivo "facilitar o acesso a informações sobre teses e dissertações defendidas junto a programas de pós-graduação do país" . Com isso, torna-se possível delinear o cenário da produção científica no Brasil sobre o tema pesquisado. Os anos de publicação foram limitados a 2011 e 2012 por serem estes os períodos disponibilizados pela instituição. A tabela para a organização de materiais incluiu o processo de categorização, seguindo as bases da análise de conteúdo. A partir da colocação das categorias primárias na tabela, originadas de palavras-chave para busca das teses e dissertações, outras categorias emergiram, refinando a busca e dando condições de analisar onde se complementam ou se relacionam.

Para compor os constitutivos de cada categoria primária foram escolhidas duas palavras-chave selecionadas, primeiramente, por contemplarem de forma abrangente a ideia inicial do estudo. Com base nas duas categorias iniciais, "esporte" e "afeto", surgem quatro categorias emergentes, apurando a pesquisa. O surgimento das categorias emergentes se deu através da leitura dos resumos das teses e dissertações encontradas, que convergiam para a temática central. Com as categorias "afeto" (240 resultados encontrados) e "esporte" (638 resultados encontrados) emergiram as categorias "afetividade na aprendizagem", "relação professor-aluno", "treinador/técnico esportivo" e "iniciação esportiva". Foram selecionadas apenas as teses e dissertações que apresentavam os termos das categorias emergentes nos resumos, nas palavras-chave ou no título. Na sequência, uma segunda leitura dos resumos, mais aprofundada, proporcionou um segundo corte que possibilitou selecionar apenas os trabalhos em que o uso desses termos estivesse relacionado ao objeto de estudo dessa pesquisa, como pode se ver na tabela abaixo:

\footnotetext{
1 Portal da CAPES, disponível em: <http://www.capes.gov.br/servicos/banco-de-teses>, acesso em: 02 jun. 2014.
} 
Tabela 1 - Distribuição dos Trabalhos Publicados na CAPES em 2011 e 2012

\begin{tabular}{llccccccc}
\hline \multirow{2}{*}{$\begin{array}{c}\text { Categorias } \\
\text { Iniciais }\end{array}$} & Categorias emergentes & $\begin{array}{c}\text { Total de } \\
\text { Trabalhos }\end{array}$ & \multicolumn{2}{c}{$\begin{array}{c}\text { Total de Trabalhos } \\
\text { Selecionados }\end{array}$} & \multicolumn{2}{c}{ Dissertações } & \multicolumn{2}{c}{ Teses } \\
\cline { 5 - 9 } & & $\mathbf{N}$ & $\%$ & $\mathbf{N}$ & $\%$ & $\mathbf{N}$ & $\%$ \\
\hline Afeto (240) e & Afetividade na Aprendizagem & 72 & 6 & 8,3 & 5 & 6,9 & 1 & 1,3 \\
Esporte (638) & Relação Professo-Aluno & 91 & 5 & 7,7 & 5 & 7,7 & 0 & 0,0 \\
& Treinador/Técnico Esportivo & 17 & 7 & 41,1 & 6 & 35,2 & 1 & 5,8 \\
& Iniciação Esportiva & 17 & 4 & 18,7 & 3 & 18,7 & 1 & 5,8 \\
\hline
\end{tabular}

Fonte: A Autora (2014).

Foram selecionadas e analisadas de forma aprofundada 22 pesquisas, das 197 identificadas e categorizadas. Esse número se deve ao fato de que apenas esses estudos sinalizaram algum tipo de aproximação com as categorias designadas para análise. Nas categorias emergentes os trabalhos relacionados à temática desse estudo representaram percentuais bastante variados no que diz respeito ao total de teses e dissertações disponíveis no banco de Teses da CAPES nos anos de 2011 e 2012. Segundo a Tabela 1, dos 72 trabalhos encontrados na categoria "afetividade na aprendizagem" 6 , o equivalente a $8,3 \%$ do total, estavam relacionados ao tema da pesquisa; na categoria "relação professor-aluno" 5 trabalhos foram encontrados, perfazendo um percentual de 7,7 do total, menor percentual dentro de todas as categorias emergentes. Na categoria "treinador/técnico esportivo" dos 17 trabalhos encontrados no total, 7 ou $41 \%$ contemplam a temática, maior percentual entre as categorias emergentes. Foram encontrados 4 trabalhos na categoria "iniciação esportiva", equivalendo a 23,5\%, das publicações relacionadas.

Também de acordo com a Tabela 1 percebe-se a maior incidência de dissertações do que de teses, sendo 19 dissertações e apenas 3 teses selecionadas no total. Nas categorias "afetividade na aprendizagem", "treinador/ técnico esportivo" e "iniciação esportiva" foi encontrada apenas uma tese em cada, incidindo, respectivamente, em $1,3 \%, 5,8 \%$ e 5,8\% do total de trabalhos encontrados com o tema. Na categoria "relação professor-aluno" nenhuma tese foi publicada no Banco de Teses da CAPES nos anos pesquisados. Esses dados evidenciam a carência de produção científica na área, principalmente no que tange às teses, pois dos 22 trabalhos que constituíram o estado de conhecimento dessa pesquisa, apenas 3 teses foram selecionadas. Esse dado pode ser um indicativo da importância de se desenvolver estudos acerca desse tema, uma vez que os percentuais demonstram, além de inexpressividade numérica, pouca construção de conhecimento relacionada ao mesmo. 
É importante também considerar, analisando o banco de dados da CAPES, o aumento da produção de trabalhos, que teve seu número bastante ampliado, do ano de 2011 para 2012. Verificou-se um total de 8 trabalhos publicados no ano de 2011 (somando todas as categorias), enquanto que em 2012 apareceram 14 pesquisas. Com isso, embora se saliente a escassez de pesquisa acerca do tema em questão, os dados relacionados aos anos de produção evidenciam que existe um crescimento de interesse pela área.

Verificou-se que 5, dos 6 trabalhos selecionados na categoria "afetividade na aprendizagem", apresentavam convergência no tema, abordando a afinidade da afetividade com a cognição, com um estreito vínculo da primeira no processo de desenvolvimento da inteligência e do pensamento. Os trabalhos também confluíram para a ideia de que a aprendizagem não pode ser dissociada da afetividade, com elementos como atitudes, crenças, valores e motivações sendo os principais fatores impactantes para o resultado da aprendizagem. Os conceitos de afetividade e suas relações com a aprendizagem apresentados nos trabalhos pesquisados seguem a mesma linha que aqueles estudados no referencial teórico dessa pesquisa sobre o estado do conhecimento, entendendo-se a importância dessa afinidade para que todos os processos inerentes à aprendizagem possam ser desencadeados. Apresentando alguns estudos analisados nessa categoria, a dissertação de Gabriela Kaiana Ferreira (2012), Investigando a Influência do Domínio Afetivo em Atividades Didáticas de Resolução de Problemas de Física no Ensino Médio, aponta para o surgimento da separação entre razão e emoção e mente e corpo nas ideias platônicas de que razão e emoção faziam parte de universos distintos. Ferreira (2012, p.232), em sua pesquisa, traz à discussão a necessidade da compreensão da interação entre cognição e afetividade para "gerenciar os afetos e assim promover uma aprendizagem mais efetiva dos conhecimentos escolares." A autora fundamenta-se na ideia de que os afetos são fator de forte influência para o envolvimento, interesse e desempenho do aluno e que o papel do professor torna-se essencial nesse processo. Beatriz Alves Paulo Cavalcanti (2011), na dissertação Representações Discentes Sobre a Afetividade nas Aulas de Inglês de Uma Escola Técnica, traz o século XXI como aquele das emoções e dos afetos, confirmando a correlação entre razão e sentimentos. A autora fala ainda da ligação entre o cognitivo e a afetividade como elemento facilitador para que cada um desenvolva suas capacidades afetivas e suas potencialidades. A pesquisa evidenciou aspectos afetivos como respeito, disponibilidade em ajudar, atitude positiva do professor como essenciais, na percepção dos alunos.

Assegurando as ideias apresentadas nas dissertações Mosquera e Stobäus (2006, p.126) afirmam que "os sentimentos têm a última palavra no que se refere à maneira como o resto do cérebro se ocupa de suas tarefas, em especial a cognição". Marchesi (2008, p. 71) acrescenta ainda a existência de "relações entre as emoções e os sentimentos, as habilidades cognitivas, a tomada de decisões e a construção da identidade", apoiando assim, as concepções versadas nos trabalhos pesquisados. É relevante também destacar que 3, dos 6 trabalhos da categoria "afetividade na aprendizagem" apresentavam de forma direta a "relação professor-aluno" como um espaço de 
construção da dimensão afetiva, mostrando, como já abordado nas bases teóricas desse estudo, que para se construir a aprendizagem dentro de um ambiente permeado pelo afeto, é preciso que esse afeto surja a partir das relações que se estabelecem entre o professor e aluno.

De uma maneira geral, os trabalhos selecionados na categoria "relação professor-aluno" consideram essa relação como o pilar dos processos de ensino e aprendizagem, abordando o tema de forma similar no que diz respeito à importância do afeto e das emoções. Todos os estudos selecionados nessa categoria consideram que a afetividade tem papel fundamental nos resultados da aprendizagem, apontando para o vínculo existente entre a afetividade na aprendizagem e a relação professor-aluno. A Dissertação selecionada nessa categoria do estado do conhecimento, Reflexões Pedagógicas: Diálogo e Afeto Enquanto Motriz Pedagógico, de Bantu Mendonca Katchipwi Sayla (2012, p. 13), infere que "a relação professor-aluno deve constituir-se num esquema horizontal de respeito e de intercomunicação", ressaltando o diálogo e o afeto como componentes relevantes a uma "aprendizagem significativa". Sayla (2012, p. 110-111) complementa também que "o desenvolvimento afetivo torna-se primordial no processo de aprendizagem, pois viabiliza as interações pertinentes ao conhecimento e a subjetividade através da qualificação do ato de aprender que inclui necessariamente a presença do docente e do discente", afirmando que o processo de aprendizagem tem seu ponto de partida nas interações subjetivas dos indivíduos. A dissertação de Liege Gasparim, Interações Na Sala de Aula: Vinculações Afetivas e a Contribuição da Pessoa Para Henry Wallon (2012, p. 12) se agrega a esse conceito entendendo que se considerarmos os laços estreitos "entre aprendizagem e emoção, pode-se supor que o afeto interfere na formação das estruturas cognitivas e que, portanto, o fortalecimento da qualidade das relações afetivas entre criança e adulto poderá contribuir efetivamente para os processos de ensino e aprendizagem." A autora traz que as atitudes e a maneira como o professor se comunica com seus alunos podem afetar seus desempenhos nas situações de aprendizagem.

Tassoni (2000) corrobora com as dissertações ao afirmar que o saber humano e os processos cognitivos estão vinculados às relações humanas e que a afetividade permeia toda a aprendizagem, uma vez que as vivências e a interação com outros sujeitos é que irão atribuir ao objeto de conhecimento um sentido afetivo. Nesse sentido, percebe-se que tanto as dissertações selecionadas nesse estado do conhecimento quanto a literatura usada para as bases teóricas desse estudo voltam-se para mesma ideia, entendendo que é na relação professor-aluno que se encontram as possibilidades de manifestações de afetividade, ponto fundamental, segundo a autora, para sobrevir a aprendizagem. Belotti e Faria (2010, p. 1) também trazem a relação professor-aluno que se desenvolve de forma positiva como uma forma de alargar as possibilidades de aprendizado, produzindo uma gama variada de resultados nos indivíduos.

Todas as produções científicas selecionadas na categoria "treinador/técnico esportivo" apontam o técnico como figura basilar na formação e conquistas dos atletas. Reinaldo Naia Cavazani (2012), na dissertação categorizada nesse estudo A Iniciação Competitiva Precoce e a Formação do Técnico Desportivo de Judô: Um Estudo de Caso 
Enfocando os Campeonatos Paulistas de 1999 Até 2011 mostra a relevância do técnico para todo o desenvolvimento esportivo da criança, fundamentalmente no que diz respeito aos cuidados com a frustração e o fracasso. Outra dissertação selecionada para essa análise do estado do conhecimento, Formação dos Treinadores de Tênis de Alto Rendimento no Brasil, de Marcelo Bittencourt Neiva de Lima (2011, p. 21) traz nas suas discussões que os treinadores são pessoas fundamentais para garantir propostas de atividades e treinos com qualidade e que são exigidas competências em muitas funções que lhes são atribuídas, indo além da mera transmissão da técnica e perpassando pelo "papel de líder, psicólogo, amigo, professor, administrador e modelo a seguir". Concorrendo com as ideias apresentadas nas pesquisas selecionadas Miranda e Bara Filho (2008, p. 151) afirmam que "o treinador constitui-se em um dos principais elos entre o jovem atleta e o esporte", reiterando que a figura do treinador é um dos pontos mais fundamentais para se desenvolver um bom programa de treinos por meio da "qualidade de seu relacionamento com os atletas". Portanto, a relação que surge entre treinador e atleta pode contribuir de maneira decisiva para que emerjam estados de afetividade, influenciando no processo de aprendizagem e desempenho. Outra concepção abordada em 4 das 7 pesquisas selecionadas nessa categoria é a formação dos treinadores, onde se assinala que a trajetória do treinador como atleta e técnico acaba por fornecer os elementos essenciais para a ação profissional, tornando-se mais importante e usual que a graduação em Educação Física. Lima (2011) também assinala em sua dissertação a importância da formação de treinadores, onde é apontada pelos próprios treinadores como elemento indispensável para a melhora na qualidade das práticas profissionais. No entanto, a dissertação traz que a formação inicial baseada em uma aprendizagem informal, por meio de um conhecimento advindo com a prática como atleta, parece contribuir de forma determinante para o ingresso na carreira e o sucesso profissional. Cavazini (2012) apresenta nas considerações de sua pesquisa que experiências vivenciadas e resultados obtidos ainda como atletas são importantes para o processo de formação de técnicos esportivos e podem ser uma forma de acúmulo de prestígio. Cavazini (2012, p. 48) ainda constatou que o "perfil pedagógico profissional do licenciado é o mais adequado para o trabalho com as crianças".

Becker (2000, p. 84) corrobora as ideias apresentadas nos trabalhos pesquisados dizendo existir grande número de atletas, que "quando sentem que se aproxima o final de sua carreira, pensam na possibilidade de seguir no mesmo esporte, na condição de treinador." O autor alerta ainda para os critérios utilizados por dirigentes para se selecionar pessoas para trabalhar com o esporte infantil. Esses dados trazem uma importante reflexão acerca da formação dos professores e treinadores de esportes, uma vez que dimensões sociais e pedagógicas podem escapar a esse tipo de instrução informal, focada, principalmente, no alto rendimento e nos resultados.

Dos 4 trabalhos selecionados na categoria "iniciação esportiva", 3 abordam claramente a contribuição da relação professor/treinador-aluno/atleta, trazendo a ideia de que o processo de formação do atleta competitivo tem sua constituição de forma significativa nessa relação. Eduardo Neves Pedrosa Di Cillo (2011) na tese de doutorado analisada 
nessa pesquisa Auto-Fala em Simulação de Esportes: Comparação dos Efeitos de Reforçamento Diferencial e Instrução no Desempenho de Iniciantes aborda o comportamento verbal como um fenômeno complexo, defendendo a ideia de que muitas relações humanas são verbais. Para Cillo $(2011$, p.4) "estudos sobre comportamento verbal, especificamente, podem contribuir substancialmente para a solução de problemas na relação entre professores/ treinadores e iniciantes". Pode-se então inferir que as formas verbais escolhidas pelo treinador na fase da iniciação esportiva podem definir significados, afetos e motivações na criança esportista. A dissertação selecionada nessa categoria de análise Processo de Formação de Atletas Competitivos Sob a Perspectiva Fenomenológico-Existencial de Thania Xerfan Melhem (2012) apresenta como unidade de significado emergente na pesquisa o vínculo com o educador-técnico. Para a autora a figura do técnico aparece com grande importância na formação esportiva de uma criança. Percebe-se também, nos discursos dos entrevistados, que o treinador representa não só a pessoa que conduz a aprendizagem esportiva, mas igualmente aquele que marca a formação humana e pessoal do iniciante no esporte. As entrevistas apresentadas na pesquisa trazem em seu discurso a lembrança do primeiro treinador, ainda na iniciação esportiva, como uma referência para a criança em todas as dimensões da sua vida. Constata-se com isso que o atleta mostra em sua trajetória esportiva, desde a iniciação, o técnico como figura importante e marcante, evidenciando "a importância da afetividade e confiança para que possa estabelecer relações" (MELHEM, 2012, p. 62). Essa abordagem traz novamente a presença da figura do professor/treinador desde as primeiras fases da iniciação esportiva e os desdobramentos das suas relações com o aluno-atleta, temática transversal, que perpassou todas as categorias de análise nessa construção do estado do conhecimento. Relevante também assinalar que, mesmo aqueles trabalhos que não trouxeram diretamente essa questão, em algum momento mencionaram o envolvimento e a importância do professor/treinador, destacando sua formação e atuação profissional. Duas pesquisas selecionadas abordaram a questão da iniciação esportiva dentro de uma concepção que enfatiza o treinamento técnico e tático, visando dentro do processo de ensino e aprendizagem a competição. Como exemplo dessa abordagem apresentase a dissertação de Melhem (2012, p. 33-34) que traz conceitos de que o esporte desenvolve "valores éticos, morais e sociais" e que "a competição é um componente importante porque é em sua relação com o esporte que é imposta a condição de cumprir aspectos como a lida com o confronto, com a disputa, e a busca pelo desafio", onde aprender a competir torna-se saudável à medida em que pode ser um importante aprendizado para todos os momentos e atividades da vida humana.

\section{Considerações finais}

As análises das Teses e Dissertações do banco de dados da CAPES dos anos de 2011 e 2012 demonstraram, em todas as categorias, que a relação professor/treinador-aluno é o ponto fundamental para que emerjam manifestações de afetividade no desenvolvimento da aprendizagem esportiva. De forma direta ou indireta as pesquisas abordaram a 
conexão da aprendizagem com a afetividade, não sendo diferente na iniciação esportiva, e apontaram para a figura do professor/treinador como peça fundamental para que sejam desencadeados os fenômenos afetivos. Os desdobramentos das suas relações com o aluno-atleta foram indicados como os principais fatores para o desenvolvimento esportivo da criança e sua permanência na modalidade, sendo também sua formação foco de estudo em vários trabalhos analisados. Os resultados trazidos nas pesquisas estudadas trouxeram a formação dos professores e treinadores de esportes como ponto importante na atuação desse profissional, revelando que, na maioria dos casos, a trajetória como atleta define suas práticas e metodologias de trabalho. Parece pertinente comentar que essa realidade merece ser analisada de forma detalhada em outros estudos, uma vez que professores e treinadores esportivos podem estar reproduzindo práticas aprendidas em seus contextos como atletas. Com isso, dimensões pedagógicas, sociais e afetivas podem não estar agregadas a esse tipo de preparo informal, que busca, principalmente, alto rendimento e resultados.

Embora esse estado do conhecimento tenha evidenciado um aumento da produção do ano de 2011 para 2012 infere-se que mais estudos sejam realizados acerca do tema, pois ainda são poucos os trabalhos nesse campo. Uma maior produção poderia levantar outras questões pertinentes no que diz respeito às influências dos afetos emergentes da relação professo/treinador-aluno na aprendizagem esportiva, podendo, inclusive, auxiliar profissionais em suas práticas.

Sabe-se também que os resultados e as discussões apresentadas nesse estudo não esgotam todas as perspectivas de análise acerca do tema, sobretudo porque o recorte temporal para o desenvolvimento dessa pesquisa foi de apenas dois anos, limitação imposta pelo período disponibilizado pela CAPES. Sugere-se que outros estudos sobre o estado do conhecimento sobre a afetividade na aprendizagem na iniciação esportiva a partir da relação professor/treinadoraluno sejam realizados, incluindo um período de tempo mais abrangente e outras bases de dados.

\section{Referências}

BARBANTI, V. O Que é Esporte? Revista Brasileira de Atividade Física e Saúde, Pelotas, v. 11, n. 1, p. 54-58, jan. 2006. Disponível em: <http://periodicos.ufpel.edu.br/ojs2/index.php/RBAFS/article/viewFile/833/840>. Acesso em: 27 abr. 2014.

BECKER JR., B. O treinador esportivo e a criança. In: BECKER JR., B. Psicologia aplicada à criança no esporte. Novo Hamburgo: FEEVALE, 2000. p. 83-115.

BELOTTI, S. H. A.; FARIA, M. A. Relação professor/aluno. Revista Eletrônica Saberes da Educação, São Roque, v. 1, n. 1, p. 1-12, 2010. Disponível em: <http://www.facsaoroque.br/novo/publicacoes/pdfs/salua.pdf > . Acesso em: 27 abr. 2014.

CAVALCANTI, B. A. P. Representações discentes sobre a afetividade nas aulas de inglês de uma escola técnica. 2011. 117f. Dissertação (Mestrado Acadêmico em Estudos da Linguagem) - Departamento de Línguas e Literaturas Estrangeiras Modernas, Universidade Federal do Rio Grande do Norte, Natal, 2011. Disponível em: <http://repositorio.ufrn.br:8080/jspui/bitstream/1/8381/1/ BeatrizAPC_DISSERT.pdf>. Acesso em: 14 jun. 2014. 
CAVAZINI, R. A. Iniciação competitiva precoce e a formação do técnico desportivo de judô: um estudo de caso dos resultados dos campeonatos paulistas de 1999 até 2011. 2012. 142f. Dissertação (Mestrado Acadêmico em Ciências da Motricidade) - Instituto de Biociências, Universidade Est.Paulista Júlio de Mesquita Filho, Rio Claro, 2012. Disponível em: <http://www.athena.biblioteca.unesp. br/exlibris/bd/brc/33004137062P0/2012/cavazani_rn_me_rcla.pdf>. Acesso em: 14 jun. 2014.

CILLO, E. N. P. D. Auto-fala em simulação de esportes: comparação dos efeitos de reforçamento diferencial e instrução no desempenho de iniciantes. 2011. 95f. Tese (Doutorado em Psicologia Experimental) - Instituto de Psicologia, Universidade de São Paulo, São Paulo, 2011. Disponível em: <http://www.teses.usp.br/teses/disponiveis/47/47132/tde-20072011-112029/publico/cillo_do.pdf>. Acesso em: 15 jun. 2014.

COSTI, M. Sala de aula, arquitetura, corpo e aprendizagem. In: FUHR, M. J. (Org.). Sob a espada de Damocles: relação dos professores com a docência e ambiente de trabalho no ensino privado. Porto Alegre: Carta Editora, 2013. p. 75-84.

DAMÁSIO, A. R. O erro de Descartes: emoção, razão e cérebro humano. 2. ed. São Paulo: Companhia das Letras, 2006.330 p.

FERREIRA, G. K. Investigando a influência do domínio afetivo em atividades didáticas de resolução de problemas de Física no ensino médio. 2012. 235f. Dissertação (Mestrado Acadêmico em Educação Cientifica e Tecnológica) - Centro de Ciências Físicas e Matemática, Centro de Ciências da Educação e Centro de Ciências Biológicas, Universidade Federal de Santa Catarina, Florianópolis, 2012. Disponível em: <http://ppgect.ufsc.br/files/2012/03/Gabriela-Kaiana-Ferreira-Disserta\%C3\%A7\%C3\%A3o-Final.pdf >. Acesso em: 14 jun. 2014.

GALlAHUE, D.; OZMUN, J.; GOODWAY, J. Compreendendo o desenvolvimento motor. Porto Alegre: AMGH, 2013.487 p.

GASPARIM, L. Interações na sala de aula: vinculações afetivas e a contribuição da pessoa para Henry Wallon. 2012. 111f. Dissertação (Mestrado Acadêmico em Educação) - Setor de Educação, Universidade Federal do Paraná, Curitiba, 2012. Disponível em: <http://www. ppge.ufpr.br/teses/M12_LIEGE\%20GASPARIN_dissertacao\%20mestrado.pdf>. Acesso em: 14 jun. 2014.

HAYWOOD, K.M.; GETCHELL, N. Desenvolvimento mMotor ao longo da vida. Porto Alegre: Artmed, 2010. 408 p.

KUNZ, E. Transformação didático-pedagógica do esporte. Ijuí: Ed. Unijuí, 2006. 160 p.

LEITE, S. A. Afetividade nas práticas pedagógicas. Temas em Psicologia, Ribeirão Preto, v. 20, n. 2, p. 355-368, dez. 2012. Disponível em: <http://pepsic.bvsalud.org/pdf/tp/v20n2/v20n2a06.pdf>. Acesso em: 11out. 2013.

LIMA, M. B. N. Formação dos treinadores de tênis de alto rendimento no Brasil. 2011. 246f. Dissertação (Mestrado Acadêmico em Ciências do Movimento Humano) - Centro de Ciências da Saúde e do Esporte, Universidade do Estado de Santa Catarina, Florianópolis, 2011. Disponível em: <http://www.tede.udesc.br/tde_busca/arquivo.php?codArquivo=2585>. Acesso em: 14 jun. 2014.

LOPES, M.; SAMULSKI; D. M.; NOCE, F. Análise do perfil ideal do treinador de voleibol das seleções brasileiras juvenis. Revista Brasileira de Ciência e Movimento, Brasília, v. 12, p. 51-55, dez. 2004. Disponível em: <http://portalrevistas.ucb.br/index.php/RBCM/ article/viewFile/586/610>. Acesso em: 01 jun. 2014.

MARCHESI, A. O bem-estar dos professores: competências, emoções e valores. Porto Alegre: Artmed, 2008.168 p.

MELHEM, T. X. O processo de formação de atletas competitivos sob a perspectiva fenomenológico-existencial. 2012. 102f. Dissertação (Mestrado Acadêmico em Educação Física) - Escola de Educação Física e Esporte, Universidade de São Paulo, São Paulo, 2012. 
Disponível em: <http://www.teses.usp.br/teses/disponiveis/39/39133/tde-02052012-082446/publico/Dissertacao_Corrigida_TMelhem.pdf>. Acesso em: 15 jun. 2014.

MIRANDA, R.; BARA FILHO, M. Construindo um atleta vencedor: uma abordagem psicofísica do esporte. Porto Alegre: Artmed, 2008. 200p.

MOSQUERA, J. J. M.; STOBÄUS, C. D. Afetividade: a manifestação de sentimentos na educação. Educação, Porto Alegre, v. 29, n. 1(58), p. 123-133, jan.-abr 2006. Disponível em: <http://www.revistaseletronicas.pucrs.br/ojs/index.php/faced/article/view/438>. Acesso em: 11 out. 2013.

ROMANOWSKI, J. P.; ENS, R. T. As pesquisas denominadas do tipo "Estado da Arte" em educação. Diálogo Educacional, Curitiba, v. 6, n. 19, p. 37-50, set.-dez. 2006. Disponível em: <http://www2.pucpr.br/reol/index.php/dialogo?dd99=pdf\&dd1=237>. Acesso em: 10 jun. 2014.

RUIZ, V. M., OLIVEIRA, M. J. V. A dimensão afetiva da ação pedagógica. Educ@ação - Rev. Ped. UNIPINHAL, Espírito Santo do Pinhal, v. 01, n. 03, p. 5-11, jan.-dez. 2005. Disponível em: <http://ferramentas.unipinhal.edu.br/ojs/educacao/include/getdoc.php?id=138 \&article=34\&mode=pdf $>$. Acesso em: 26 abr. 2014.

SANTANA, W. C. Pedagogia do esporte na infância e complexidade. In: PAES, R. R.; HERMES, F. B. (Org.). Pedagogia do esporte: contextos e perspectivas. Rio de Janeiro: Guanabara Koogan, 2005. p. 1-22.

SANTOS, F. M. A Importância da afetividade no processo de ensino e aprendizagem como mediadora da práxis educativa no ensino superior. Revista UNI, Imperatriz, ano 2, n. 2, p. 111-122, jan.-jul. 2012. Disponível em: <http://www.unisulma.edu.br/Revista_UniEd2 Santos7.pdf>. Acesso em: 01 nov. 2011.

SAYLA, B. M. K. Reflexões pedagógicas: diálogo e afeto enquanto motriz pedagógico. 2012. 150f. Dissertação (Mestrado Acadêmico em Educação) - Unidade de Articulação Acadêmica em Educação, Humanidades e Artes, Universidade do Sul de Santa Catarina, Tubarão, 2012. Disponível em: <http://aplicacoes.unisul.br/pergamum/pdf/104908_Bantu.pdf>. Acesso em: 13 jun. 2014.

TANI, G. et al. Educação física escolar: fundamentos de uma abordagem desenvolvimentista. São Paulo: EPU, 1988.

TASSONI, E. C. M. Afetividade e aprendizagem: a relação professor-aluno. In: REUNIÃO ANUAL DA ANPEd, 23., 2000, Caxambu. Anais, Caxambu: ANPEd, 2000. Disponível em: <http://23reuniao.anped.org.br/textos/2019t.PDF>. Acesso em: 12 jun. 2014.

\section{Endereço para correspondência:}

Michelle Guiramand

Rua José Gomes, 123/201 - Tristeza

91910-280 Porto Alegre, RS, Brasil

E-mail:<michelle.guiramand@acad.pucrs.br>

Recebido em: jun./2014

Aceito em: ago./2014 